\title{
Dissociation reactions of hydrogen in remote plasma-enhanced chemical-vapor-deposition silicon nitride
}

\author{
Christoph Boehme ${ }^{\text {a) }}$ and Gerald Lucovsky \\ Department of Physics, North Carolina State University, Raleigh, North Carolina 27695-8202
}

(Received 24 October 2000; accepted 9 July 2001)

\begin{abstract}
Dominant hydrogen dissociation reactions during annealing of hydrogenated amorphous-silicon nitride were determined by comparison of the bond density dynamics with various reaction models. The sample material was produced with remote plasma-enhanced chemical-vapor deposition, deposited at high-ammonia-to-silane flow ratios (ammonia rich). The heat treatment was performed with rapid thermal annealing at various annealing temperatures and times as well as samples containing different stoichiometries and isotopes (hydrogenated and deuterated). The experiments showed that hydrogen loss during annealing is mostly due to molecular hydrogen $\left(\mathrm{H}_{2}\right)$ release as long as $\mathrm{SiH}$ bonds are contained in the film. After their exhaustion, an ammonia $\left(\mathrm{NH}_{3}\right)$ producing reaction prevails at temperatures between 600 and $900{ }^{\circ}$ C. (C) 2001 American Vacuum Society.
\end{abstract} [DOI: 10.1116/1.1398538]

\section{INTRODUCTION}

The concentration of bonded hydrogen in amorphoussilicon nitride films is reduced significantly during postdeposition anneal at temperatures above the deposition temperature. It has been shown that the dominating mechanism for the reduction of ammonia-rich remote plasma-enhanced chemical-vapor-deposited (RPECVD) silicon nitride $\left(\mathrm{Si}_{x} \mathrm{~N}_{y} \mathrm{H}_{z}\right)$ is a "fast" (low-activation-energy, highdiffusivity) diffusion of small molecules that have dissociated out of the silicon-nitride network, while other mechanisms like atomic diffusion do not play an important role. ${ }^{1} \mathrm{~A}$ better qualitative and quantitative understanding of these chemical reactions, especially in regard to different siliconnitride stoichiometries, can contribute to the explanation of bulk and surface passivation processes through postdeposition anneal of solar cell antireflection (AR) coatings.

\section{EXPERIMENTS}

The experiments were based on rapid thermal annealing of stack systems with a $\mathrm{Cz}-\mathrm{Si}$ substrate underneath a RPECVD silicon-nitride film deposited at high-ammonia-tosilane ratios. The first measurement series was carried out on the samples with an ammonia-to-silane deposition flow ratio of $R=20$. In order to ensure comparability with previous diffusion experiments, ${ }^{1} 400-\AA ̊ \AA-$ thick silicon nitride was used. However, for reduction of the large signal-to-noise ratio of the Fourier transform infrared (FTIR) measurements, a higher thickness of $800 \AA$ was then used for samples with deposition flow ratios of $R=4$ and $R=10$. The quantitative dynamics of the process was observed by measuring the hydrogen bond area densities after the anneal at different anneal times. In order to get information about $\mathrm{SiH}-$ and $\mathrm{NH}-$ bond interactions and for reproducibility tests, all experiments were carried out twice-with films deposited with deuterated ammonia $\left(\mathrm{ND}_{3}\right)$ as well as films deposited with regular hydrogenated ammonia $\left(\mathrm{NH}_{3}\right)$. The matrix of

\footnotetext{
${ }^{\text {a)} P r e s e n t ~ a d d r e s s: ~ H a h n-M e i t n e r-I n s t i t u t ~ B e r l i n, ~ K e k u l e ́ s t r a s s e ~ 5, ~}$ D-12489 Berlin, Germany; electronic mail: boehme@hmi.de
}

this experiment contained, therefore, three deposition flow ratios $(R=4, R=10$, and $R=20)$ times two isotopes ( $\mathrm{H}$ and D) times six anneal times $(20,45,70,200,400$ and $800 \mathrm{~s})$ times six anneal temperatures $(500,600,700,800,900$, and $1000^{\circ} \mathrm{C}$ ). At each sample the area bond densities of $\mathrm{SiD}$, $\mathrm{SiH}, \mathrm{ND}$, and $\mathrm{NH}$ were measured with FTIR spectroscopy.

\section{DEPOSITION AND ANNEAL}

The sample stacks were deposited by remote plasmaenhanced chemical-vapor deposition in a flowing afterglow reactor configuration ${ }^{2,3}$ at a temperature of $200^{\circ} \mathrm{C}$. Before deposition of the silicon nitride layer, a $4 \AA$ oxide layer was produced with plasma oxidation in order to improve the $c$-Si/nitride interface quality. All three ammonia-to-silane ratios were high in order to produce silicon nitride with low dielectric functions, a desirable property of good AR coatings. After the deposition, the rapid thermal anneal (RTA) in an Ar environment was carried out at the times and temperatures mentioned above. For this process a Heatpulse 610 ex situ instrument was used.

\section{FTIR AND SIMS MEASUREMENTS}

A Nicolet Magna IR 750 FTIR spectrometer was used to determine the postanneal hydrogen- and deuterium-bond content of the 216 samples. The quantification was carried out by integration of the stretching mode absorbance peaks of $\mathrm{SiD}$ bonds $\left(\approx 1573 \mathrm{~cm}^{-1}\right)$, SiH bonds $\left(\approx 2182 \mathrm{~cm}^{-1}\right)$, ND bonds $\left(\approx 2479 \mathrm{~cm}^{-1}\right)$, and NH bonds $\left(\approx 3336 \mathrm{~cm}^{-1}\right){ }^{4}$ The area densities were then obtained by use of IR-scattering cross sections according to Lanford ${ }^{5}$ and Kim. ${ }^{6}$ Because of the ammonia-rich deposition of the samples, the $\mathrm{SiH}$ and $\mathrm{SiD}$ densities were below the detection limits in most of the samples. Only a few samples at low anneal temperatures and short anneal times had recognizable $\mathrm{SiH}$ or $\mathrm{SiD}$ peaks. These, however, could not reveal much quantitative information because of the high-signal-to-noise ratio. Table I shows the anneal times after which no $\mathrm{SiH}$ and $\mathrm{SiD}$ could be detected. 
TABLE I. Anneal times after which $\mathrm{SiH}-$ or SiD-bond densities reduced below the detection limit.

\begin{tabular}{lcccccc}
\hline \hline$T\left({ }^{\circ} \mathrm{C}\right)$ & $R=4, D$ & $R=4, H$ & $R=10, D$ & $R=10, H$ & $R=20, D$ & $R=20, H$ \\
\hline 500 & $800 \mathrm{~s}$ & $800 \mathrm{~s}$ & $70 \mathrm{~s}$ & $200 \mathrm{~s}$ & $70 \mathrm{~s}$ & $0 \mathrm{~s}$ \\
600 & $400 \mathrm{~s}$ & $45 \mathrm{~s}$ & $0 \mathrm{~s}$ & $0 \mathrm{~s}$ & $20 \mathrm{~s}$ & $0 \mathrm{~s}$ \\
700 & $20 \mathrm{~s}$ & $0 \mathrm{~s}$ & $0 \mathrm{~s}$ & $0 \mathrm{~s}$ & $0 \mathrm{~s}$ & $0 \mathrm{~s}$ \\
800 & $20 \mathrm{~s}$ & $0 \mathrm{~s}$ & $0 \mathrm{~s}$ & $0 \mathrm{~s}$ & $0 \mathrm{~s}$ & $0 \mathrm{~s}$ \\
900 & $0 \mathrm{~s}$ & $0 \mathrm{~s}$ & $0 \mathrm{~s}$ & $0 \mathrm{~s}$ & $0 \mathrm{~s}$ & $0 \mathrm{~s}$ \\
1000 & $0 \mathrm{~s}$ & $0 \mathrm{~s}$ & $0 \mathrm{~s}$ & $0 \mathrm{~s}$ & $0 \mathrm{~s}$ & $0 \mathrm{~s}$ \\
\hline \hline
\end{tabular}

The quantitative analysis was, therefore, carried out on the NH- and ND-bond densities. The plots in Fig. 1 show the time developments of the ND and NH peaks at different anneal temperatures for the example of a deuterated siliconnitride film with an ammonia-to-silane deposition ratio of $R=10$. One can clearly recognize the increasing bond loss with increasing time and temperature.

The FTIR-derived area densities were then calculated as described above and for comparability reasons normalized on the initial densities of the respective samples. The results as well as the error bars for the entire measurement series are displayed in Figs. 2, 3, and 4. Since the values displayed are based on peak-integrated intensities, the error margins depend on the noise of the FTIR spectra as well as the spectral resolution of the spectrometer. The latter value was only given as an upper limit, which means that the margins of the error bars represent only an upper limit of one $\sigma$ as well. The relative errors of the samples with flow ratio 20 are significantly higher in comparison to the samples for flow ratios 10 and 4 because of the worse signal-to-noise ratio that was caused by the different sample thicknesses.

The secondary ion mass spectroscopy (SIMS) measurements were carried out by Evans East, NJ. The process involved $3 \mathrm{keV} \mathrm{Cs}^{+}$primary ions that were sputtered at a $60^{\circ}$ angle of incidence. The use of SIMS was carried out only supportively on a few samples in order to confirm the applicability of the "fast diffusion after chemical dissociation" model for the data interpretation as discussed elsewhere. ${ }^{7}$
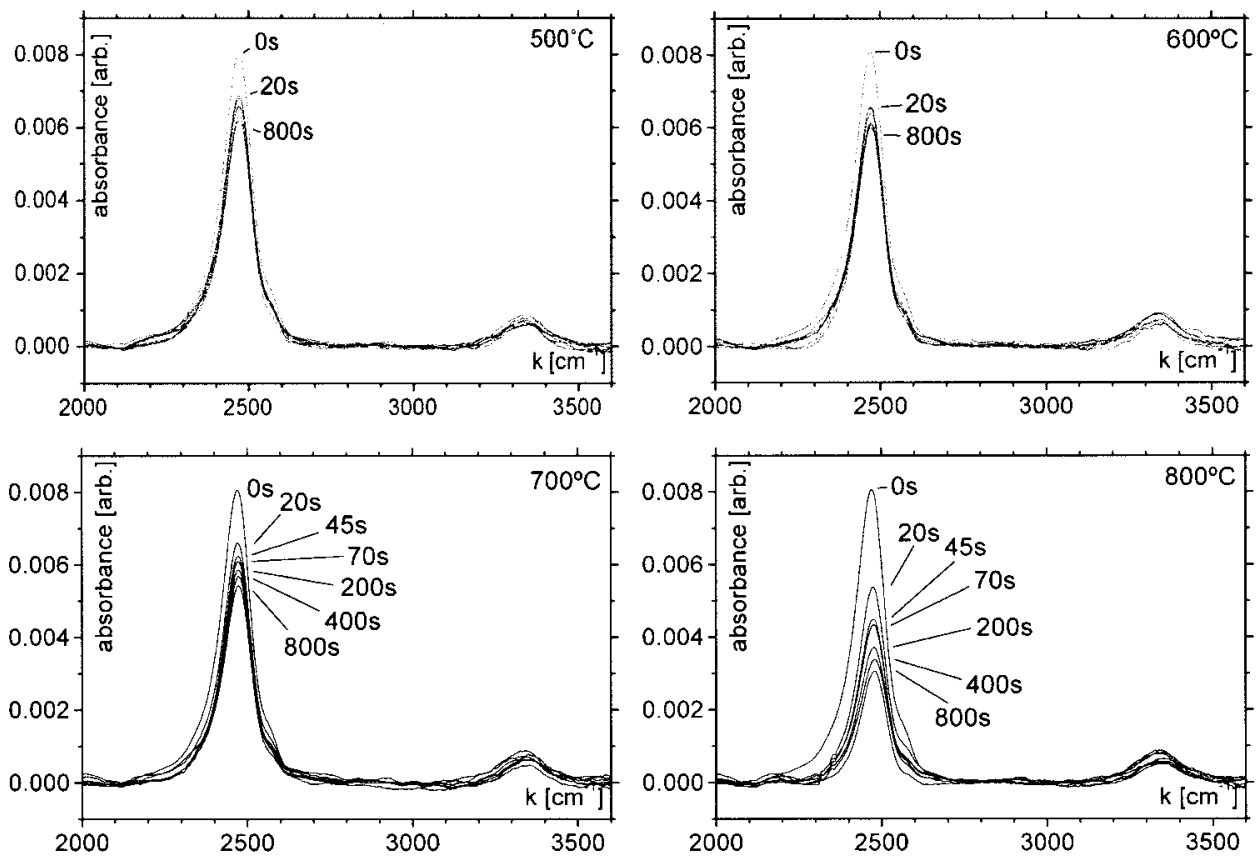

FIG. 1. FTIR spectra of deuterated silicon-nitride films annealed at several temperatures and times. The deposition flow ratio was 10 . The ammonia isotope was $\mathrm{ND}_{3}$. Quantification was carried out for the ND peaks at $2479 \mathrm{~cm}^{-1}$ only since the NH peaks at $3336 \mathrm{~cm}^{-1}$ are too small for reasonable relative errors.
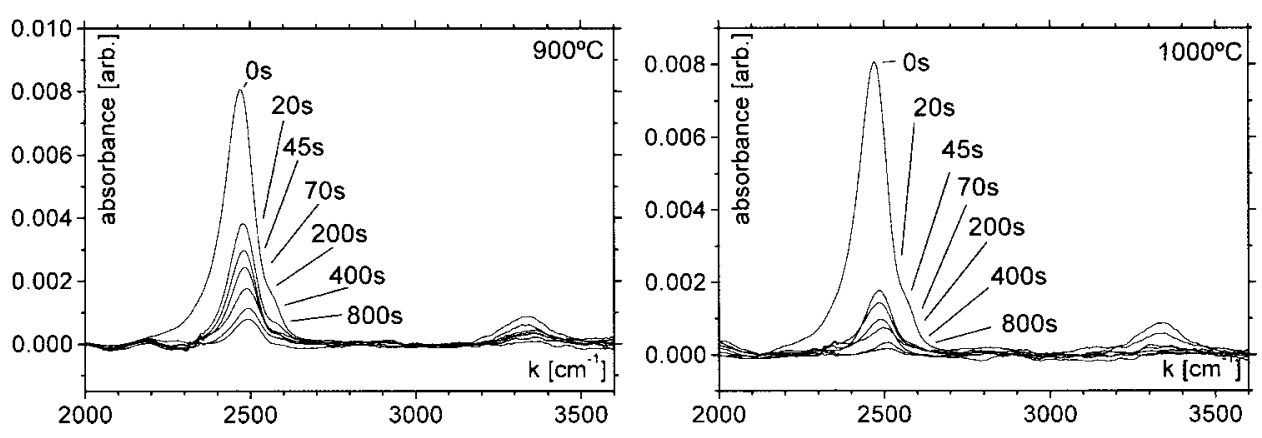

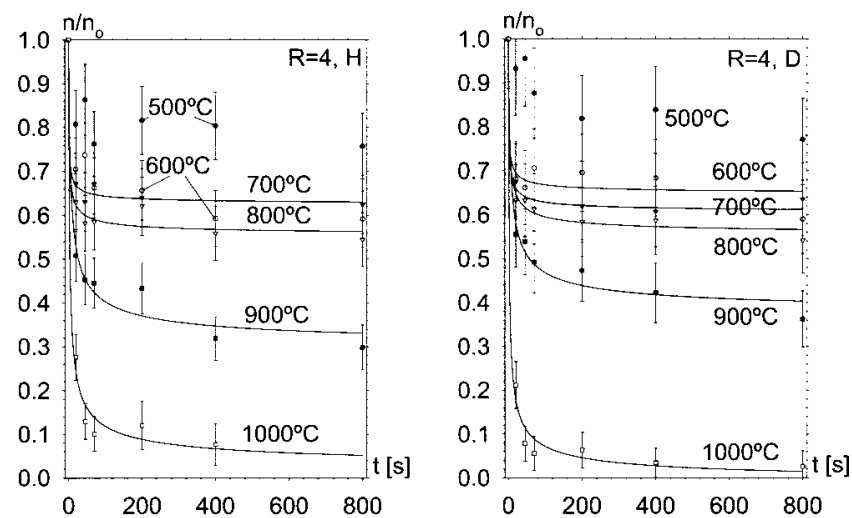

FIG. 2. Time evolution of the normalized NH/ND-area bond densities for samples deposited with hydrogenated/deuterated ammonia at an ammoniato-silane deposition flow ratio of 4 and fit results for the ammonia dissociation mechanism.

Figure 5 shows the deuterium, hydrogen, and oxygen profiles for a sample with an ammonia-to-silane deposition flow ratio of 10 , annealed for $800 \mathrm{~s}$ at $1000^{\circ} \mathrm{C}$. The postanneal density of deuterium and hydrogen is constant within the 80-nmthick nitride film. As explained in the following section, a depth inhomogeneity would have had to develop, if chemical dissociation of hydrogen or deuterium had not been dominant during annealing.

\section{DISSOCIATION MODEL IN SILICON NITRIDE}

Atomic diffusion processes of hydrogen have activation energies at about $3 \mathrm{eV} .{ }^{8}$ As shown elsewhere, ${ }^{1,9}$ such mechanisms lead to strong hydrogen density gradients within a silicon-nitride layer at anneal temperatures, anneal times, and for sample geometries as given in the experiments described above. If a postanneal hydrogen profile is homogeneous, a transport mechanism of hydrogen must be present that equalizes the density gradients very fast (low activation energy) and leaves, nevertheless, large quantities of hydrogen unaffected. This observation can be explained by rapid diffusion of dissociation products whose activation energies are in the
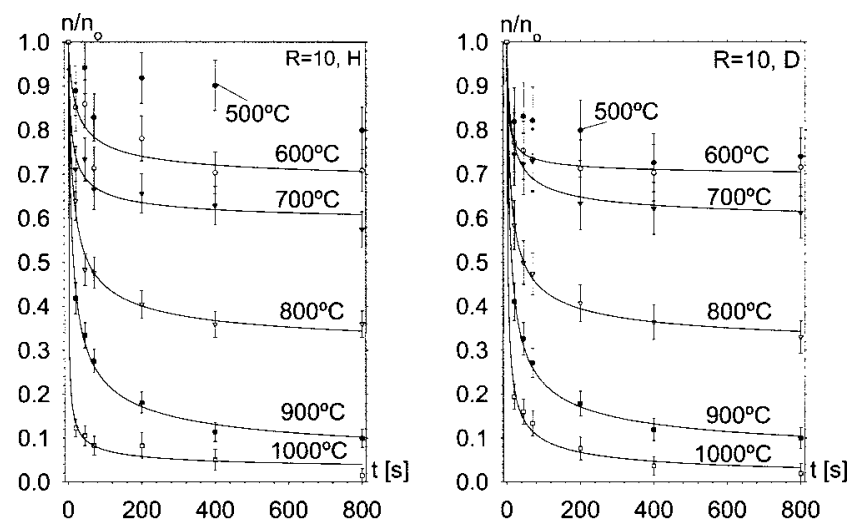

FIG. 3. Time evolution of the normalized NH/ND-area bond densities for samples deposited with hydrogenated/deuterated ammonia at an ammoniato-silane deposition flow ratio of 10 and fit results for the ammonia dissociation mechanism.
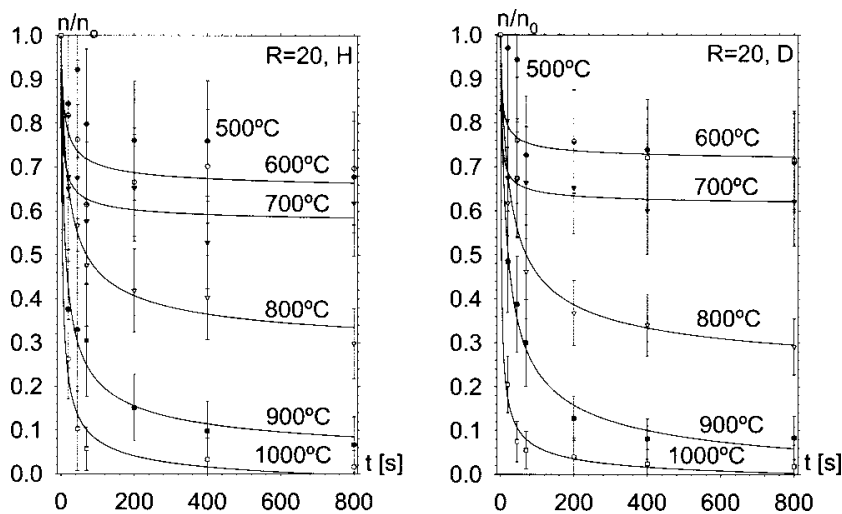

FIG. 4. Time evolution of the normalized NH/ND-area bond densities for samples deposited with hydrogenated/deuterated ammonia at an ammoniato-silane deposition flow ratio of 20 and fit results for the ammonia dissociation mechanism.

meV range. ${ }^{1}$ The assumption that small dissociation products diffuse rapidly out of the system implies that the chemical reactions between the large covalent network and the small diffusing molecules never remain in a chemical equilibrium with constant reaction rates in both directions unless the trivial state is reached where these rates and the concentration of the molecules are zero. As long as small molecules are in the network, there is an escape rate out of the system and an equilibrium cannot be reached. For the qualitative interpretation of the data, various chemical reactions of hydrogen in a silicon-nitride network were considered. Since the diffusion processes of the molecular species are very high, any concentration gradient is equalized immediately, which means faster than the time resolution of the measurements. The dissociation of small molecules was anticipated, therefore, processes involving molecular hydrogen $\left(\mathrm{H}_{2}\right)$, ammonia $\left(\mathrm{NH}_{3}\right)$, hydracine $\left(\mathrm{N}_{2} \mathrm{H}_{4}\right)$, single $\mathrm{NH}$ and $\mathrm{NH}_{2}$

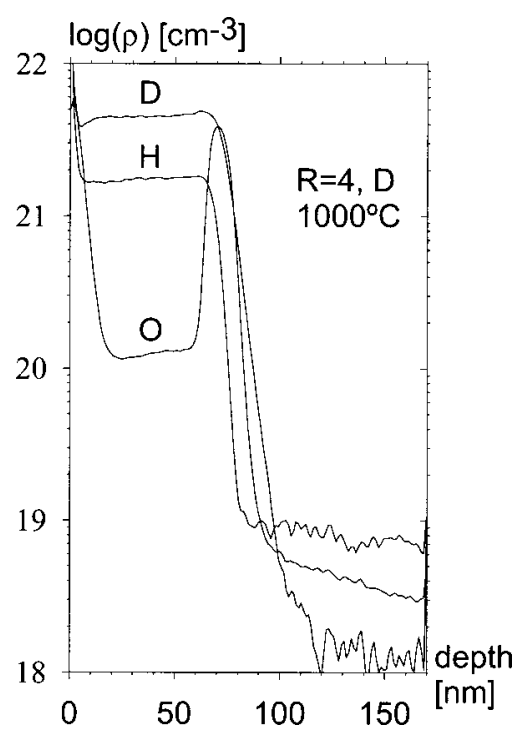

FIG. 5. SIMS profiles of the sample with an ammonia-to-silane deposition flow ratio of 4 after an $800 \mathrm{~s}$ anneal at $1000{ }^{\circ} \mathrm{C}$. The $\mathrm{H}$ and $\mathrm{D}$ densities in the nitride region are mostly constant, which confirms the assumed depth independence of the deuterium- and hydrogen-dissociation reactions. 
TABLE II. Chemical reactions of hydrogenated silicon nitride into molecular hydrogen, ammonia, silane, disilane, and hydracine.

\begin{tabular}{|c|c|c|c|c|c|}
\hline & $E_{\text {bond }}^{\text {educ }}$ & Reaction & $E_{\text {bond }}^{\text {prod }}$ & $\Delta E$ & \\
\hline 1 & $7.78 \mathrm{eV}$ & $2 \mathrm{~N}-\mathrm{H} \leftrightarrow \mathrm{H}_{2}+\mathrm{N}-\mathrm{N}$ & $6.23 \mathrm{eV}$ & $1.55 \mathrm{eV}$ & $\begin{array}{l}\text { Unlikely for low } T \\
\text { since } \Delta E>0\end{array}$ \\
\hline 2 & $6.34 \mathrm{eV}$ & $2 \mathrm{Si}-\mathrm{H} \leftrightarrow \mathrm{H}_{2}+\mathrm{Si}-\mathrm{Si}$ & $6.83 \mathrm{eV}$ & $-0.49 \mathrm{eV}$ & Unlikely since $n_{\mathrm{Si}-\mathrm{H}} \ll$ \\
\hline 3 & $7.06 \mathrm{eV}$ & $\mathrm{Si}-\mathrm{H}+\mathrm{N}-\mathrm{H} \leftrightarrow \mathrm{H}_{2}+\mathrm{Si}-\mathrm{N}$ & $8.92 \mathrm{eV}$ & $-1.86 \mathrm{eV}$ & $\begin{array}{l}\text { Likely as long as enough } \\
\mathrm{Si}-\mathrm{H} \text { bonds are present }\end{array}$ \\
\hline 4 & $12.68 \mathrm{eV}$ & $4 \mathrm{Si}-\mathrm{H} \leftrightarrow \mathrm{SiH}_{4}$ & $13.20 \mathrm{eV}$ & $-0.52 \mathrm{eV}$ & Unlikely since $n_{\mathrm{Si}-\mathrm{H}} \ll$ \\
\hline 5 & $22.19 \mathrm{eV}$ & $7 \mathrm{Si}-\mathrm{H} \leftrightarrow \mathrm{Si}_{2} \mathrm{H}_{6}+\mathrm{NH}$ & $25.79 \mathrm{eV}$ & $-3.6 \mathrm{eV}$ & Unlikely since $n_{\mathrm{Si}-\mathrm{H}} \ll$ \\
\hline 6 & $12.2 \mathrm{eV}$ & $\mathrm{Si}-\mathrm{N}+2 \mathrm{~N}-\mathrm{H} \leftrightarrow \mathrm{NH}+\mathrm{Si}-\mathrm{H}$ & $7.06 \mathrm{eV}$ & $5.14 \mathrm{eV}$ & Unlikely since $\Delta E>0$ \\
\hline 7 & $23.87 \mathrm{eV}$ & $\mathrm{Si}-\mathrm{N}+5 \mathrm{~N}-\mathrm{H} \leftrightarrow 2 \mathrm{NH}_{2}+\mathrm{Si}-\mathrm{H}$ & $19.11 \mathrm{eV}$ & $4.76 \mathrm{eV}$ & Unlikely since $\Delta E>0$ \\
\hline 8 & $23.87 \mathrm{eV}$ & $5 \mathrm{~N}-\mathrm{H}+\mathrm{Si}-\mathrm{N} \leftrightarrow \mathrm{Si}-\mathrm{H}+\mathrm{N}_{2} \mathrm{H}_{4}$ & $21.01 \mathrm{eV}$ & $2.86 \mathrm{eV}$ & Unlikely since $\Delta E>0$ \\
\hline 9 & $11.67 \mathrm{eV}$ & $\mathrm{Si}_{2} \mathrm{~N}-\mathrm{H}+2 \mathrm{~N}-\mathrm{H} \leftrightarrow 2 \mathrm{Si}-\mathrm{N}+\mathrm{NH}_{3}$ & $12.10 \mathrm{eV}$ & $-0.43 \mathrm{eV}$ & $\begin{array}{l}\text { Likely as long as enough } \\
\mathrm{N}-\mathrm{H} \text { bonds are present }\end{array}$ \\
\hline
\end{tabular}

groups, as well as silane $\left(\mathrm{SiH}_{4}\right)$ and disilane $\left(\mathrm{Si}_{2} \mathrm{H}_{6}\right)$, were taken into consideration. Some of these processes are illustrated in Table II.

In order to find all possible reactions, one has to employ a systematic strategy based on finding all solutions of a system of linear equations that takes the isometric conditions of the respective reactions into account. ${ }^{7}$ The solutions of this systematic search were subjected to an enthalpie calculation based on data by Sanderson. ${ }^{10}$ Most of the reactions turned out to be endothermal and only a few reactions yielding very simple molecules were exothermal. Some of these reactions, however, require many $\mathrm{SiH}$ bonds as reactants and are, therefore, also unlikely since the deposited films have only very low $\mathrm{SiH}$ densities.

From the different dissociation reactions the loss dynamic of the respective reactant was then obtained with a simple chemistry textbook model. ${ }^{11}$ The reaction dynamics of a chemical reaction

$$
X_{1} E_{1}+X_{2} E_{2}+\cdots+X_{n} E_{n} \leftrightarrow Y_{1} P_{1}+Y_{2} P_{2}+\cdots+Y_{m} P_{m},
$$

where $E_{i}$ and $P_{i}$ denote the reactants and products, while $X_{i}$ and $Y_{i}$ their isometric factors, is described in terms of the loss of its reactant concentration $n_{E_{i}}$ which is the difference between the forward reaction rate coefficient $k_{f}$ times the reactant concentrations and the reverse reaction rate coefficient $k_{r}$ times the product concentrations. This simple rate model yields a system

$$
-\frac{d n_{E_{j}}}{d t}=k_{f} \prod_{i=0}^{n} n_{E_{i}}^{X_{i}}-k_{r} \prod_{i=0}^{m} n_{P_{i}}^{X_{i}},
$$

of ordinary differential equations.

This model was then combined with the properties of the given system under the assumptions that:

- All reverse reaction velocities are assumed to be zero. Since the product diffusivity leads to the loss of a dissoci- ated molecule immediately after its appearance, the concentration can never reach levels where the reverse reactions become important.

- The reaction of $\mathrm{NH}$ and $\mathrm{SiH}$, as well as their deuterated counterparts, are possible only down to a certain concentration limit $n^{\text {stat }}$. Below this value the locally fixed $\mathrm{H}$ bonds are to far apart from each other for undergoing chemical reactions. Therefore, in a solid, the initial density $n_{i}$ of a substance can be split into its static not changing part and its dynamic part:

$$
n_{i}=n_{i}^{\mathrm{dyn}}+n_{i}^{\text {stat }}
$$

- Reactions 2, 4, and 5 in Table II are not expected to play a role since $\mathrm{Si}-\mathrm{H}$ bonds in silicon nitride with highammonia-to-silane ratios have a very low density.

- Reactions 1, 6, 7, and 8 in Table II are not expected to play a role since they are endothermal.

- Reaction 3 in Table II is expected to occur since it is strongly exothermal. It consumes as many $\mathrm{SiH}$ bonds as $\mathrm{NH}$ bonds $\left(n_{\mathrm{SiH}}^{\mathrm{dyn}}=n_{\mathrm{NH}}^{\mathrm{dyn}}\right)$. Consequently, the dynamics of this reaction can be described with

$$
-\frac{d n_{\mathrm{NH}}^{\mathrm{dyn}}}{d t}=k_{3} n_{\mathrm{NH}}^{\mathrm{dyn}} n_{\mathrm{SiH}}^{\mathrm{dyn}}=k_{3}\left(n_{\mathrm{NH}}^{\mathrm{dyn}}\right)^{2} .
$$

The solution of this quadratic ordinary differential equations is

$$
n_{\mathrm{NH}}^{\mathrm{dyn}}(t)=\frac{1}{k_{3} t+b},
$$

where $b$ is a constant determined by the initial conditions.

- Reaction 9 in Table II (Fig. 8) is exothermal as well and its velocity is proportional to the third power of $n_{\mathrm{NH}}^{\mathrm{dyn}}$, yielding a cubic ordinary differential equation:

$$
-\frac{d n_{\mathrm{NH}}^{\mathrm{dyn}}}{d t}=k_{4}\left(n_{\mathrm{NH}}^{\mathrm{dyn}}\right)^{3}
$$

with the solution 


$$
n_{\mathrm{NH}}^{\mathrm{dyn}}(t)=\frac{1}{\sqrt{2 k_{4} t+b}} .
$$

\section{DATA FIT}

The resulting equations provide a link between the dissociation model and the bond density measurements made with FTIR. By comparison of the FITR results of the dissociation experiment with the predicted time evolution of the model, the dominant chemical dissociation mechanism can be identified, and moreover, by fit of the model functions, a relative quantification of the reaction rates at different temperatures is possible.

Based on the model functions given above, fits were carried out for each density versus time curve whose results are shown in Figs. 2, 3, and 4. The software used for the fit procedures was SIGMA PLOT 5.0. While the fit results for the given bond density data with the solution of the quadratic differential equation [Eq. (5)] hardly obtained correlation factors above 0.4 , the solution of the cubic differential equation [Eq. (7)] was in most cases above 0.9 and in all cases above 0.8 except for $500{ }^{\circ} \mathrm{C}$. For this temperature the solution of Eq. (4) obtained its highest value of 0.45 . The fits displayed in the graphs are based on the ammonia dissociation function

$$
y(x)=y_{0}+\frac{1}{\sqrt{2 a x+b}},
$$

where $y$ represents the fitted data, which is the normalized area density of the silicon-nitride films, $x$ the time variable, and $y_{0}, a$, and $b$ are the fit variables that were used. All the displayed functions seem to represent the right model for temperatures above $500{ }^{\circ} \mathrm{C}$.

\section{INTERPRETATION}

The high-correlation factors of the cubic differential equation solution [Eq. (5)] at temperatures above $500{ }^{\circ} \mathrm{C}$ indicate that the dissociation of $\mathrm{NH}$ bonds directly into ammonia (Table II, reaction 4) seems to be the most likely process. At $500{ }^{\circ} \mathrm{C}$ a different mechanism appears to be taking place. As shown in Table I, the $\mathrm{SiH}$ and $\mathrm{SiD}$ bonds that are initially present in the film system do not or only gradually vanish at this temperature. At higher temperatures silicon hydrogen bonds seem to disappear much faster than the anneal time resolution of $20 \mathrm{~s}$ can display. This initial $\mathrm{SiH}$ reduction can only be due to a rapid $\mathrm{SiH}$ consuming mechanism, which means an exothermal process with high enthalpy. Reaction 3 in Table II consumes as many ND or NH bonds as SiD or $\mathrm{SiH}$ bonds and is the reaction with the highest-energy release found. It seems to be dominant at $500{ }^{\circ} \mathrm{C}$, whereas reaction 9 does not play a role because of its much lower reaction enthalpy. At higher temperatures, reaction 3 becomes so fast that all the silicon bonds are consumed at the time of the first measurement after $20 \mathrm{~s}$, which stops reaction 3, and reaction 9 can prevail. This explanation is also in agreement with
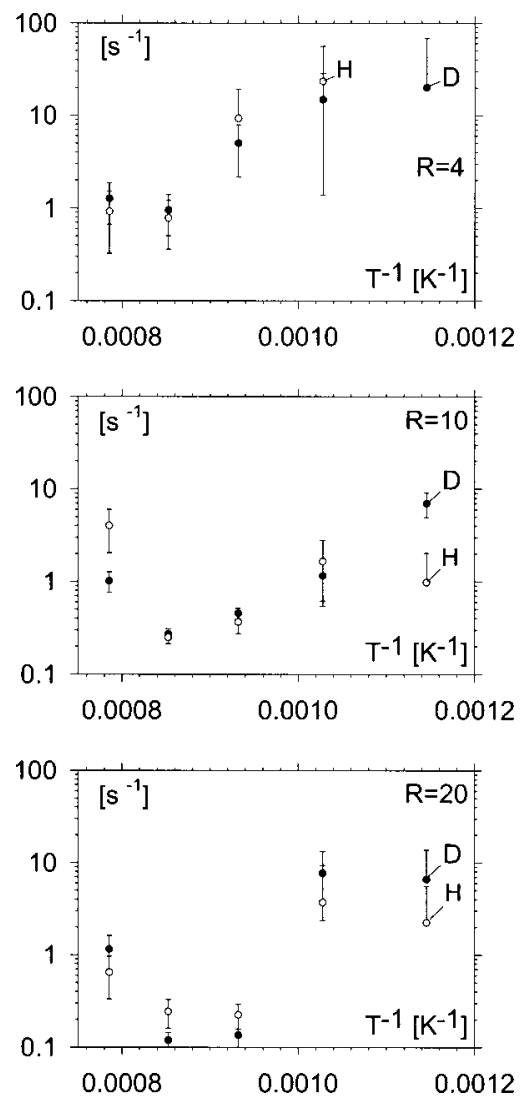

FIG. 6. Fit results of the reaction rate factors of all samples vs the inverse temperature. Unlike gaseous substances, the reaction rates decrease below $1000^{\circ} \mathrm{C}$.

previous studies on the anneal of ammonia-rich deposited silicon nitride by $\mathrm{Zu}$ et al., ${ }^{12}$ were reaction 3 in Table II was observed with spectroscopic methods.

Above $500{ }^{\circ} \mathrm{C}$ the fit with Eq. (8) works extraordinary well and reveals the data for $y_{0}, a$, and $b$. Fit parameter $y_{0}$ represents the static offset of the NH or ND density part that does not dissociate at the given temperature. As one can see in Eq. (8), the parameter $b$ is the square of inverse initial dynamic NH or ND density and, therefore, related to $y_{0}$ through Eq. (3). It turns out that most of the fits result in $y_{0}+1 / \sqrt{b} \approx 1$. Figure 6 displays the results for parameter $a$, which is proportional to the reaction rates because of Eq. (7). Figure 7 displays the results for $1 / \sqrt{b}$.

The interpretation of the reaction rate curves is difficult because of the few available data points. The general behavior of the temperature dependence is recognizable nevertheless. The reaction rate data reproduced for the sample deposited with different hydrogen isotopes but not for different deposition flow ratios. Unlike the reaction rates of species in gaseous environments, the reaction rate is not proportional to the Arrhenius law which predicts a strong increase with higher temperature. In fact, all six samples show an almost exponential decay of the reaction rate with increasing temperature between 600 and $900^{\circ} \mathrm{C}$, which is the range where the reaction 9 fit function [Eq. (8)] achieved the highest correlation factors. The reason for this behavior could be related 

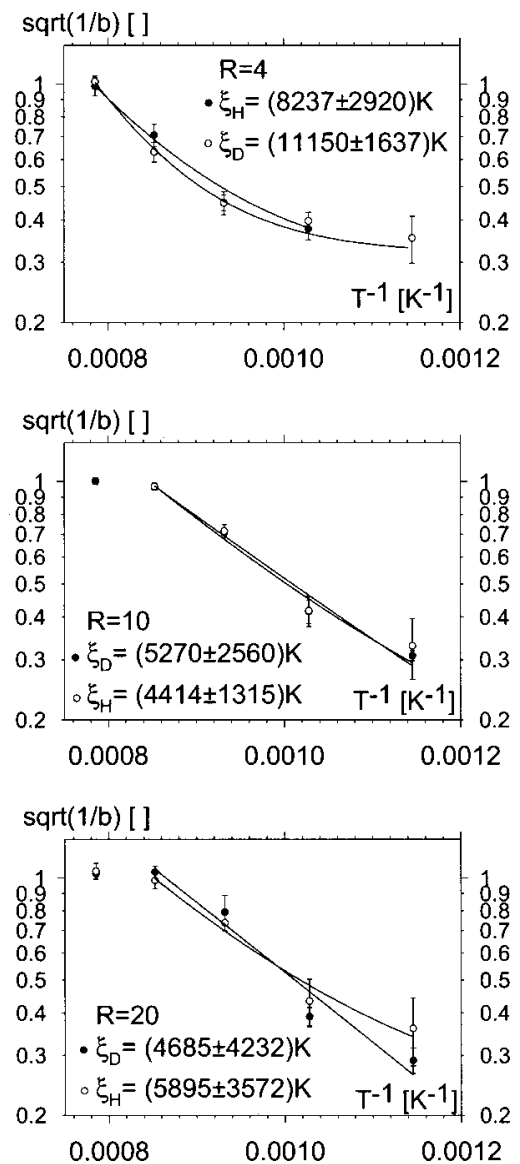

FIG. 7. Fit results of the static bond concentration vs inverse temperature. Below $1000^{\circ} \mathrm{C}$ an Arrhenius fit was possible. The fit variable $\xi$ represents the fraction of the activation energy over the Boltzmann factor.

to the higher amount of bonds that dissociate at higher temperatures forcing the bonds to react at much lower densities which reduces the probability of the bonds coming close enough for a chemical reaction.

Another feature of fit parameter $a$ is the deviation from this rate reduction at $1000^{\circ} \mathrm{C}$. The reaction rate of all six samples increases between 900 and $1000{ }^{\circ} \mathrm{C}$, turning the decay into an increase. It appears that a thermal activation barrier is overcome at this temperature range which enhances the reaction.

The graphs of the inverse square root of fit parameter $b$ (Fig. 7) exhibit strong proportionality to the Boltzmann factor. In all cases, the dynamic ND or NH density increase strongly with increasing temperature. The graphs displayed were fitted with an exponential decay with offset. The offset, which causes a curvature at some of the logarithmic graphs, is introduced in order to take an initial fast $\mathrm{SiH}+\mathrm{NH}$ reaction into account. The fit showed a strong agreement for $R=4$ over the entire temperature range, while for $R=10$ and $R$ $=20$ between 600 and $900^{\circ} \mathrm{C}$. This indicates also different dominating chemical processes at the edges of the measured range. The results of this fit are shown in Table III. They show an agreement within their error ranges between films with equal deposition flow ratios and different hydrogen isotopes. Differences occur between the different deposition
TABLE III. Activation energies of static bond density reduction.

\begin{tabular}{lrc}
\hline \hline Sample & Decay factor $(\mathrm{K})$ & $\Delta E(\mathrm{meV})$ \\
\hline R4D & $11150 \pm 1637$ & $961 \pm 141$ \\
R4H & $8237 \pm 2920$ & $710 \pm 252$ \\
R10D & $5270 \pm 2560$ & $454 \pm 220$ \\
R10H & $4414 \pm 1315$ & $380 \pm 113$ \\
R20D & $4685 \pm 4232$ & $404 \pm 365$ \\
R20H & $5895 \pm 3572$ & $508 \pm 308$ \\
\hline \hline
\end{tabular}

flow ratios. While $R=4$ samples have activation energies at about $800 \mathrm{meV}, R=10$ and $R=20$ films are at about 450 $\mathrm{meV}$, which is in agreement with the fits that were already made for the diffusion experiments of $20 \mathrm{~s}$ annealed samples ${ }^{1,9}$ and also with previous results by $\mathrm{Zu}$ et al. ${ }^{12}$

\section{SUMMARY AND CONCLUSIONS}

Annealing of RPECVD silicon nitride, deposited with high-ammonia-to-silane flow ratios, leads at low temperatures $\left(\approx 500^{\circ} \mathrm{C}\right)$ to a rapid $\mathrm{H}$ loss due to the reaction of $\mathrm{NH}$ and $\mathrm{SiH}$ bonds into $\mathrm{H}_{2}$ and $\mathrm{Si}-\mathrm{N}$ bonds. This process is limited by the amount of $\mathrm{SiH}$ bonds in the system. At higher temperatures this process takes place even faster and a slower dissociation reaction prevails after the exhaustion of the $\mathrm{SiH}$ bonds. This second reaction (Fig. 8) produces ammonia out of the three $\mathrm{NH}$ bonds and is able to push the overall $\mathrm{H}$ loss of the system further since it is not limited by the low $\mathrm{Si}-\mathrm{H}$-bond content. Unlike chemical reactions of gaseous substances, this process has a decreasing reaction rate between $\approx 600$ and $\approx 900^{\circ} \mathrm{C}$ since the increasing $\mathrm{H}$ loss leads to lower densities, resulting in lower interaction probabilities of the NH-bond systems in the film. At $\approx 1000^{\circ} \mathrm{C}$ a third dissociation process is activated, pushing the $\mathrm{H}$ loss even further and increasing the reaction rates.

The understanding of these dissociation mechanisms can be applied to the improvement of postdeposition anneal treatments of solar cell antireflection coatings. Annealing of $\mathrm{Si}_{x} \mathrm{~N}_{y} \mathrm{H}_{z}$-AR coatings has been shown to be a passivation process for the underlying crystalline bulk silicon. ${ }^{13,14}$ A possible $\mathrm{H}$ diffusion from the coating into the bulk can only take place if the hydrogen content at the nitride-silicon interface can be kept at a sufficient time at a sufficient level. Such a high $\mathrm{H}$ content could probably be achieved either by a very long time furnace anneal at a temperature low enough to prevent ammonia dissociation $\left(600^{\circ} \mathrm{C}\right.$ and below) or by RTA in an environment with high ammonia partial pressure.

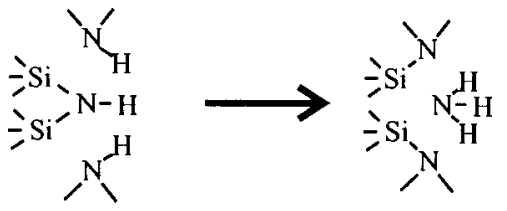

FIG. 8. Exothermal ammonia development out of three NH bonds (See Table II, reaction 9). 
${ }^{1}$ C. Boehme and G. Lucovsky, J. Appl. Phys. 88, 6055 (2000).

${ }^{2}$ G. Lucovsky, P. D. Richard, D. V. Tsu, S. Y. Lin, and R. J. Markunas, J. Vac. Sci. Technol. A 4, 681 (1986).

${ }^{3}$ G. Bruno, P. Capezutto, and A. Madan, Plasma Deposition of Amorphous Silicon Based Materials (Academic, Boston, MA, 1995).

${ }^{4}$ S. Pinchas and I. Laulicht, Infrared Spectra of Labelled Compounds (Academic, London, 1971), p. 49.

${ }^{5}$ W. A. Lanford and M. J. Rand, J. Appl. Phys. 49, 2473 (1978).

${ }^{6}$ S. S. Kim, Ph.D. thesis, North Carolina State University (1990).

${ }^{7}$ C. Boehme, Diplomarbeit, Ruprecht-Karls-Universität, Heidelberg (2000).

${ }^{8}$ W. M. Arnold Bik, R. N. H. Linnsen, F. H. P. M. Habraken, and W. F. van der Weg, Appl. Phys. Lett. 56, 2530 (1990).
${ }^{9}$ C. Boehme and G. Lucovsky, Mater. Res. Soc. Symp. Proc. 609, A26.7.1 (2000).

${ }^{10}$ R. T. Sanderson, Chemical Bonds and Bond Energy (Academic, New York, 1971), pp. 187 and 190.

${ }^{11}$ H. Hartmann, J. Heidberg, H. Heydmann, and G. H. Kohlmaier, Chemische Elementarprozesse (Springer, Heidelberg, 1968).

${ }^{12}$ Z. Zu, G. Santos-Filho, G. Stevens, M. J. Williams, and G. Lucovsky, J. Vac. Sci. Technol. A 13, 607 (1995).

${ }^{13}$ F. Duerinckx, J. Szlufcik, K. De Clercq, and P. De Schepper, Proceedings of the 13th European Photovoltaic Solar Energy Conference, Nice (1995), Vol. 2, p. 1493.

${ }^{14}$ J. Szlufcik, K. De Clercq, P. De Schepper, J. Poortmans, A. Buczkowski, J. Nijs, and R. Mertens, Proceedings of the 12th European Photovoltaic Solar Energy Conference, Amsterdam (1994), Vol. 1, p. 1018 (unpublished). 